\title{
Effect of Hydrated Lime Stabilization on Consistency, Shear Strength and Compaction Properties of Sulaimani CL Soil, Northern Iraq
}

\author{
Tavga Aram Abdalla ${ }^{1}$ and Nihad Salih ${ }^{2}$ \\ ${ }^{1}$ University of Sulaimani \\ ${ }^{2}$ Affiliation not available
}

April 28, 2020

\begin{abstract}
Cohesive soils present difficulties in construction projects because of usually contain expansive clay minerals. However, the engineering properties of cohesive soils can be stabilized by using various techniques. The aim of the research is to discover the influences of using hydrated lime on the consistency, compaction, and shear strength properties of clayey soil samples from Sulaimnai city, northern Iraq. The proportions of added hydrated lime are $0 \%, 2.5 \%, 5 \%, 7.5 \%$ and $10 \%$ to the natural soil sample. The results yielded considerable effects of hydrated lime on the engineering properties of the treated soil sample and developed its strength. The soil's liquid limit, plasticity index, and optimum moisture content were decreased with the increase of hydrated lime percent. While the soil's plastic limit and maximum dry density were increased. Also, the soil's unconfined compressive strength was significantly increased with the hydrated lime content increase. The oedometer test results produced a notable decrease in the compressibility characteristics of the lime-treated soil sample. Hence, hydrated lime is successfully contributed and can be considered as an effective material to improve the strength, compressibility and consistency properties of the cohesive soils in Sulaimani city.
\end{abstract}

\section{Hosted file}

Effect of Hydrated Lime Stabilization on Consistency, Shear Strength and Compaction Properties available at https : //authorea.com/users/294648/articles/440724-effect-of-hydrated-lime-stabilizationon-consistency-shear-strength-and-compaction-properties-of-sulaimani-cl-soil-northern-iraq 